\title{
Remote Cerebellar Haemorrhage after Spinal Surgery
}

\author{
Tarkan Calisaneller, Cem Yilmaz, Ozkan Ozger, Hakan Caner, Nur Altinors
}

Can. J. Neurol. Sci. 2007; 34: 483-484

Remote cerebellar haemorrhage $(\mathrm{RCH})$ is a rare but potentially lethal complication of spinal surgery resulting from inadvertent opening of the dura. The precise mechanism of this type of haemorrhage remains undetermined. Magnetic resonance imaging (MRI) may show a 'Zebra sign' representing the horizontal curvilinear configuration of haemorrhage between the cerebellar folia.

\section{Case PResentation}

A 67-year-old female was admitted to our clinic with back and bilateral leg pain for five years. Despite a right L4-5 discectomy a year ago, her complaints gradually increased in severity. She described severe neurogenic claudication after 15 meters of walking. Lumbar MRI revealed L5-S1 grade-2 spondylolisthesis according to the Meyerding classification. Neurological examination revealed grade $4 / 5$ power in the left external hallucis longus muscle according to the MRC scale. She had a past history of headache, investigated with cranial MRI, which displayed diffuse cerebral and cerebellar atrophy. The patient had no previous history of hypertension or any other systemic disease and her blood work including the coagulation studies was normal (platelet count: 286.000 per mL, INR: 1). She was operated and a decompressive L5-laminectomy with L4-L5S1 posterior transpedicular screw-rod fixations was performed. During surgery, the dural sac was inadvertently opened. Cerebrospinal fluid leakage was observed and sealed with a muscle-fascia graft. The patient was mobilized on the second postoperative day. On the eighth postoperative day, she complained of unsteadiness and mild headache; neurological examination revealed gait ataxia. A cranial CT on the same day revealed bilateral cerebellar haemorrhage with surrounding edema. The next day, cranial MRI and MR angiography was performed confirming bilateral haemorrhages in the cerebellar hemispheres (Figure 1a,b). She was placed on a bed rest and given analgesic medication. Follow-up cranial CTs revealed total resolution of the haemorrhages. The rest of the clinical course was uneventful.

\section{Discussion}

Remote cerebellar haemorrhage after spinal surgery, first described by Chadduck in 1981 , is a rare but potentially lethal complication resulting from inadvertent opening of the dura. ${ }^{1}$ The incidence of $\mathrm{RCH}$ after supratentorial surgery was reported between $0.2 \%$ and $4.9 \%{ }^{2,3}$ However, $\mathrm{RCH}$ after spinal surgery is rarely reported in the literature and its incidence is lower than after supratentorial surgery. ${ }^{4}$ Several mechanisms such as cerebellar 'lag' leading to stretch and occlusion of the cerebellar veins may be important in causing cerebellar haemorrhage. These may have caused a venous infarction, transient traction and kinking of the cerebellar arteries followed by reperfusion haemorrhage, or rupture of the venous structures secondary to increased venous pressure. However, remote cerebellar haemorrhage involves more than the territory of a single vein and usually does not demonstrate edema or cerebellar swelling. The precise mechanism of $\mathrm{RCH}$ is unknown., ${ }^{4}$ Our patient had cerebellar atrophy on her previous cranial MR scan. Because of the atrophy, the perivascular spaces may have been enlarged with less support of blood vessels. After the CSF leakage, she may have had excessive cerebellar shift and this may have contributed to the development of the hemorrhage in our patient. The abnormality seen on MR imaging is described as the 'Zebra sign' refers to the horizontal curvilinear configuration of the haemorrhage inbetween the cerebellar folia. ${ }^{6}$ Other causes of cerebellar haemorrhage (e.g. hypertension, anticoagulation, aneurysms, vascular malformations or tumors) should be considered in the differential diagnosis. The role of patient positioning (supine, prone or sitting) in the development of $\mathrm{RCH}$ is also reported as insignificant in the literature. ${ }^{5}$ Remote Cerebellar Haemorrhages can be asymptomatic and detected incidentally on radiological examinations. The clinical presentation may vary from mild headache and dizziness to severe neurological detoriation or even death depending on the size of the haemorrhage. In a recent review of the literature, Konya et al reported that one out of ten patients with $\mathrm{RCH}$ had died, five patients had residual disability and four patients recovered. ${ }^{7}$ Treatment of $\mathrm{RCH}$ depends on the neurological status of the patient. Small haemorrhages causing mild

From the Baskent University Faculty of Medicine, Neurosurgery Department, Beyin Cerrahisi B-blok zemin kat, Hoca Cihan Mahallesi, Saray caddesi, Konya, Turkey. Received November 21, 2006. AcCePted In FinAl FORM June 18, 2007. Reprint requests to: Tarkan Calisaneller, Baskent Universitesi Hastanesi, Beyin Cerrahisi B-blok zemin kat, Hoca Cihan Mahallesi, Saray caddesi, No. 1 Selcuklu, Konya, 42080, Turkey. 


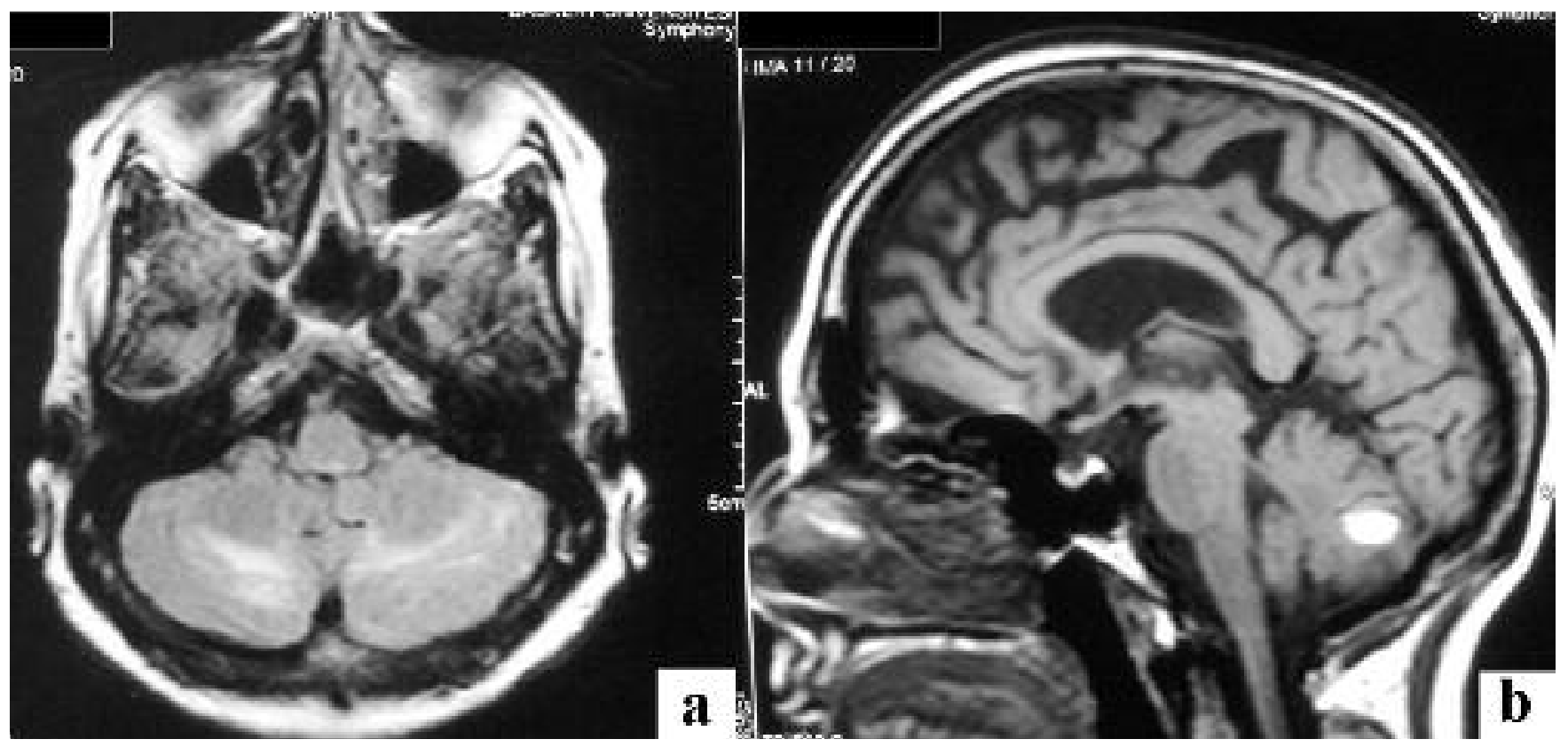

Figure: Postoperative Flair axial (a) and T-1 weighted sagittal MRI (b) displaying acute cerebellar haemorrhage inbetween cerebellar folia (zebra sign).

symptoms can be treated conservatively by bed rest and analgesics. Large haemorrhages causing significant brainstem compression, hydrocephalus or neurological detoriation should be treated by surgical intervention.

Remote cerebellar haemorrhage is a rare but potentially life threatening condition. Patients with unexplained neurological symptoms or detoriation after spinal surgery complicated with CSF leakage should be evaluated carefully and a cranial imaging with CT or MRI should be promptly performed.

\section{REFERENCES}

1. Chadduck WM. Cerebellar haemorrhage complicating cervical laminectomy. Neurosurgery. 1981; 9(2): 185-9.

2. Papanastassiou V, Kerr R, Adams C. Contralateral cerebellar hemorrhagic infarction after pterional craniotomy: report of five cases and review of the literature. Neurosurgery. 1996; 39(4): 841-51; discussion 851-2.

3. Toczek MT, Morrell MJ, Silverberg GA, Lowe GM. Cerebellar hemorrhage complicating temporal lobectomy. Report of four cases. J Neurosurg. 1996; 85(4): 718-22.

4. Brockmann MA, Groden C. Remote cerebellar haemorrhage: a review. Cerebellum. 2006; 5(1): 64-8.
5. Friedman JA, Ecker RD, Piepgras DG, Duke DA. Cerebellar haemorrhage after spinal surgery: report of two cases and literature review. Neurosurgery. 2002; 50(6): 1361-3; discussion $1363-4$.

6. Brockmann MA, Nowak G, Reusche E, Russlies M, Petersen D. Zebra sign: cerebellar bleeding pattern characteristic of cerebrospinal fluid loss. Case report. J Neurosurg. 2005; 102(6): 1159-62.

7. Konya D, Ozgen S, Pamir MN. Cerebellar hemorrhage after spinal surgery: case report and review of the literature. Eur Spine J. 2006; 15(1): 95-9. 